\title{
GEOSUL
}

\section{ANÁLISE DA ESTRUTURA ESPACIAL E FUNCIONAL DA PAISAGEM APLICADA AO PLANEJAMENTO DA CONSERVAÇÃO DA NATUREZA NO MUNICÍPIO DE ITAJAÍ, SANTA CATARINA, BRASIL}

\author{
Angelina da Silva Coelho ${ }^{1}$ \\ Rosemeri Carvalho Marenzi ${ }^{2}$ \\ Oscar Benigno $\mathrm{Iza}^{3}$ \\ Vanessa Angélica Costa Souza ${ }^{4}$ \\ Camila Longarete ${ }^{5}$
}

Resumo: A crescente urbanização do bioma Mata Atlântica demanda conhecer os processos em nível de paisagem e planejar o uso racional dos recursos naturais, atendendo a questões socioeconômicas e de conservação da biodiversidade. O objetivo deste estudo foi analisar a estrutura espacial e funcional da paisagem da região delimitada pela orla e morrarias das praias do município de Itajaí, Santa Catarina, e subsidiar a criação de uma Área de Proteção Ambiental (APA). A construção de um mapa de uso e cobertura do solo, a determinação das espécies-modelo da flora e suas interações com a fauna local são o cerne metodológico que permitiu elucidar a distribuição espacial da matriz, manchas e corredores de paisagem, bem como os processos paisagísticos funcionais existentes na área, e que devem ser considerados no planejamento da conservação.

Palavras-chave: Ecologia da paisagem; Uso e cobertura do solo; Interações planta-animal

\section{LANDSCAPE SPATIAL AND FUNCTIONAL ANALYSIS APPLIED TO NATURE CONSERVATION PLANNING IN ITAJAÍ, SANTA CATARINA, BRAZIL}

\begin{abstract}
The increasing urbanization observed in Atlantic Forest biome demands to know the processes at the landscape level to plan the rational use of natural resources, attending socioeconomic and biodiversity conservation issues. This study aimed to analyze the spatial and functional structure of the landscape of the region bounded by the border and hills of the beaches in Itajaí, Santa Catarina, and then subsidize the creation of an Environmental Protection Area (EPA). The construction of a land use and cover map, the determination of the model-species of the flora and their interactions with the local fauna are the methodological core that allowed to elucidate the spatial distribution of the matrix, patches and landscape corridors, it also allowed to understand the functional processes of landscape that should be considered in the conservation planning.
\end{abstract}

Keywords: Landscape ecology; Land use and land cover; Plant-animal interactions

\footnotetext{
${ }^{1}$ Mestre em Ciência e Tecnologia Ambiental pela Universidade do Vale do Itajaí, Itajaí, SC. Email: genharia.angelina@gmail.com

${ }^{2}$ Doutor em Ciências Florestais pelo Programa de Pós-Graduação em Engenharia Florestal da Universidade Federal do Paraná, Curitiba, PR. Email: merimarenzi@univali.br

${ }^{3}$ Mestre em Biologia Vegetal pela Universidade Federal de Santa Catarina, Florianópolis, SC. Email: oscar@univali.br

${ }^{4}$ Bióloga pela Universidade do Vale do Itajaí, Itajaí, SC. Email: vanessa.acs@ gmail.com

${ }^{5}$ Oceanógrafa pela Universidade do Vale do Itajaí, Itajaí, SC. Email: camilalongarete@ gmail.com
} 


\section{ANÁLISIS ESPACIAL Y FUNCIONAL DEL PAISAJE APLICADO A LA PLANIFICACIÓN DE LA CONSERVACIÓN DE LA NATURALEZA EN ITAJAÍ, SANTA CATARINA, BRASIL}

Resumen: La creciente urbanización del bioma Mata Atlántica requiere conocer los procesos a nivel de paisaje y planear el uso racional de los recursos naturales, a fin de atender las cuestiones socioeconómicas y de conservación de la biodiversidad. El objetivo de este estudio fue analizar la estructura espacial y el funcionamiento del paisaje de la región delimitada por la orilla y los cerros de las playas de la ciudad de Itajaí, Santa Catarina, y subsidiar la creación de un Área de Protección Ambiental (APA). La construcción de un mapa de uso y cobertura del suelo, la determinación de las especies-modelo de la flora y sus interacciones con la fauna local son el eje metodológico que permitió esclarecer la distribución espacial de la matriz, parches y corredores de paisaje, así como los procesos paisajísticos funcionales existentes en el área, y que deben de ser considerados en el planeamiento de conservación.

Palabras clave: Ecología del paisaje; Uso y cobertura del suelo; Interacciones planta-animal

\section{INTRODUÇÃO}

A adoção de padrões lineares de crescimento econômico que desconsideram os processos de retroalimentação e resiliência dos sistemas naturais levou o Homem ao limite da disponibilidade de recursos e fomenta a construção de uma sociedade problemática do ponto de vista socioambiental.

As evidências de tal problemática no Brasil se traduzem, por exemplo, nas taxas de desmatamento, que só na Amazônia Legal, entre os anos de 2010 e 2013 foram da ordem de $23880 \mathrm{~km}^{2}$ (INPE, 2015), uma área equivalente a aproximadamente 1/4 de Santa Catarina. No bioma Mata Atlântica, entre 2014 e 2015, foram desmatados $184 \mathrm{~km}^{2}$, com relação às tipologias vegetais Mangue e Restinga, ambas pertencentes a este bioma, o desmatamento foi da ordem de 4 e 55 ha, respectivamente, somente no Estado de Santa Catarina (SOSMA, 2016).

Com relação à biodiversidade, Pimm et al. (2014) estimam que a taxa atual de extinção de espécies no mundo seja hoje mil vezes maior do que a normal e ainda pode estar subestimada. A fragmentação dos biomas e sua implicação na redução da biodiversidade evidencia a necessidade de ordenar o uso e a ocupação do território para conservar os ambientes naturais. Em resposta à fragmentação desses ambientes, a criação de áreas protegidas é o principal suporte à conservação da biodiversidade segundo a IUCN (2017). Entre os diferentes tipos de áreas protegidas previstas pela legislação brasileira, se destacam as Unidades de Conservação (UC), que possuem um ato legal de criação com uma série de especificidades e categorias, mas sempre de relevante interesse ecológico (Brasil, 2000). 
No litoral centro-norte de Santa Catarina, o município de Itajaí é um exemplo do acentuado processo de urbanização em curso na zona costeira brasileira. Este processo vem provocando uma série de manifestações populares em favor da conservação dos ambientes naturais da cidade, especialmente das morrarias que circundam a planície costeira, e que se caracterizam por serem manchas remanescentes de Floresta Atlântica. A pressão popular pela conservação tornou a construção de um Complexo Turístico Habitacional localizado na porção Norte da Praia Brava alvo de um Termo de Acordo Judicial (TAJ), determinando a implantação de uma Área de Proteção Ambiental (APA) em suas adjacências.

Neste cenário, o objetivo deste estudo foi analisar a estrutura espacial e funcional da paisagem tentando compreender parte dos processos ecológicos na porção terrestre da região onde se pretende criar a UC. Buscou-se compreender a relação da disposição espacial dos elementos paisagísticos com o padrão funcional da paisagem, considerando neste caso, os potenciais dispersores (espécies- chave) das espécies arbóreas (espécies-modelo).

\section{ESTRUTURA ESPACIAL DA PAISAGEM}

A estrutura espacial da paisagem pode ser dividida em três elementos principais: a matriz, as manchas e os corredores (Odum e Barret, 2007). Do ponto de vista da conservação da natureza uma paisagem é composta por diferentes ecossistemas, habitats e tipos de vegetação e diferentes usos da terra. Em contrapartida, a paisagem é maior do que simplesmente a soma das partes que a compõe (Troll, 1971).

Para Wiens (2002) os elementos matriz, manchas e corredores apresentam uma configuração espacial própria, podendo ser compreendida como um Sistema de Informações Geográficas (SIG), um conjunto de camadas sobrepostas e integradas, cujo resultado de suas combinações é uma nova propriedade. O ramo da Ecologia Clássica conhecido como Ecologia da Paisagem, busca compreender tais combinações e propriedades, com ênfase nas causas e consequências da heterogeneidade ou do padrão espacial destas camadas. O mesmo autor pondera que a configuração espacial da paisagem pode ter efeitos importantes numa grande variedade de processos ecológicos.

Ao elemento dominante da paisagem dá-se o nome de matriz (Forman e Godron, 1981; Forman, 1995). Contudo, além de possuir a maior área de cobertura da paisagem, a matriz é aquela que apresenta a maior conectividade, desempenhando o papel também dominante no funcionamento do sistema ecológico que se estabelece na paisagem analisada (Barnes, 2000). 
As manchas, por sua vez, são áreas que podem ser consideradas homogêneas e distintas das áreas adjacentes e são classificadas, segundo Barnes (2000), em manchas de distúrbio, manchas remanescentes, manchas de recurso ambiental e manchas introduzidas, cada uma delas representando uma função ecológica no ambiente. Sabidamente, as manchas de vegetação isoladas tendem ao desaparecimento devido à fragmentação (Fernandez, 2000) e, deste modo, no contexto de conservação da biodiversidade a conectividade entre as manhas, deve ser avaliada sob o risco de perder a efetividade de medidas conservacionistas, daí a importância dos corredores de paisagem.

Os elementos paisagísticos estruturais de formato linear são os chamados corredores e, de forma natural ou planejada, frequentemente conectam as manchas, permitindo o fluxo genético das espécies na área. Odum e Barret (2007) consideram que os corredores podem ser classificados de acordo com sua origem em: corredores remanescentes, corredores de perturbação, corredores plantados, corredores regenerados e corredores naturais ou de recurso. Da mesma forma que os corredores têm denominações em função de sua origem, Forman (1995) identificou cinco funções ecológicas destes elementos: (1) habitat; (2) condutor; (3) filtro; (4) fonte e (5) sumidouro. Cada uma destas funções será analisada na configuração espacial da área de estudo.

Uma paisagem submetida ao processo de fragmentação invariavelmente ocasiona a perda de habitats e pode ser entendida como o grau de ruptura de uma unidade da paisagem, inicialmente contínua (Cullen et al., 2012). Neste sentido, Marenzi (2004) considera que alguns processos ecológicos, além de dependerem da configuração das manchas, estão submetidos à conectividade existente entre elas. Para Forman (1995), a conectividade das manchas na matriz da paisagem relaciona-se com a eficiência dos fluxos de energia, de matéria e de espécies, e que em última análise tais fluxos refletem na resistência da paisagem com relação às mudanças.

Ainda sobre a conectividade da paisagem, ela pode ser caracterizada em conectividade espacial e conectividade funcional; a primeira diz respeito à união geográfica entre manchas do mesmo tipo, enquanto que a segunda se refere ao fato de espécies ou propágulos ter a possibilidade de mover-se de uma mancha a outra (Burel e Baudry, 2004). 


\section{PADRÃO FUNCIONAL DA PAISAGEM - INTERAÇÃO PLANTA-ANIMAL}

Segundo Marenzi (2004) as interações que se estabelecem entre os elementos da paisagem são determinadas pelos aspectos climáticos, geomorfológicos, hidrológicos e edáficos, associados aos fatores bióticos. Ainda, para a autora, a vegetação surge como resultado dessas relações e, sua manutenção é determinada pela eficiência na polinização e na dispersão de sementes, esta que é definida como o transporte de propágulos - sementes ou fragmentos da planta - por meio de vários agentes abióticos ou biológicos, segundo Kollmann (2000), destacando-se as aves.

Connell (1978) já afirmava que as florestas tropicais estão sujeitas a distúrbios e alterações naturais que variam em intensidade, frequência e área afetada, e Martini e Santos (2007) alegam que tais distúrbios produzem diferentes implicações em suas principais fontes de regeneração, que são a chuva de sementes, ou seja, a dispersão de sementes pelo ar, o banco de sementes, o crescimento de indivíduos presentes antes do distúrbio, e também a rebrota de caules e raízes. Considerando que a Mata Atlântica é um bioma predominantemente em processo de regeneração, o planejamento da conservação nestas áreas deve considerar estas barreiras, tendo em conta que a dispersão de propágulos realizada por animais (zoocoria) é a estratégia de dispersão adotada por mais da metade das espécies arbóreas, superando a dispersão realizada pelo vento, água ou outras formas de dispersão (Wunderle, 1997).

Especificamente, sobre as florestas tropicais, como é o caso da Mata Atlântica, Howe (1982) destaca que pelo menos $50 \%$ e frequentemente $75 \%$ ou mais das espécies arbóreas produzem frutos carnosos adaptados para o consumo de aves e mamíferos com vistas à dispersão zoocórica. Neste trabalho, considera-se que o fenômeno de dispersão zoocórica, pode caracterizar ou mesmo estabelecer um padrão ou estrutura funcional na paisagem atestado pela presença dos indivíduos arbóreos mais bem-sucedidos associados a uma fauna sabidamente dispersora de seus propágulos. Entende-se, ainda, havendo tal padrão, ele constitui-se de um mecanismo imbricado, interdependente e retroalimentado, cuja investigação científica tem o potencial de oferecer boas reflexões com relação à conservação e ao manejo de ambientes naturais, mas especificamente de áreas protegidas, como a APA em processo de criação. 


\section{ÁREA DE ESTUDO}

A região onde se pretende implantar a Área de Proteção Ambiental - APA e objeto deste estudo está localizada no litoral centro-norte do Estado de Santa Catarina, mais especificamente na zona costeira do município de Itajaí (Figura 1). Trata-se de uma localidade caracterizada por um conjunto de atributos naturais com paisagens de relevante beleza cênica e elevado valor cultural e histórico para o município. Apresenta baixa densidade demográfica, mas contém núcleos habitacionais predominantemente unifamiliares já consolidados.

Figura 1: Localização do município de Itajaí, SC, Brasil; com destaque da área de estudo em vermelho.

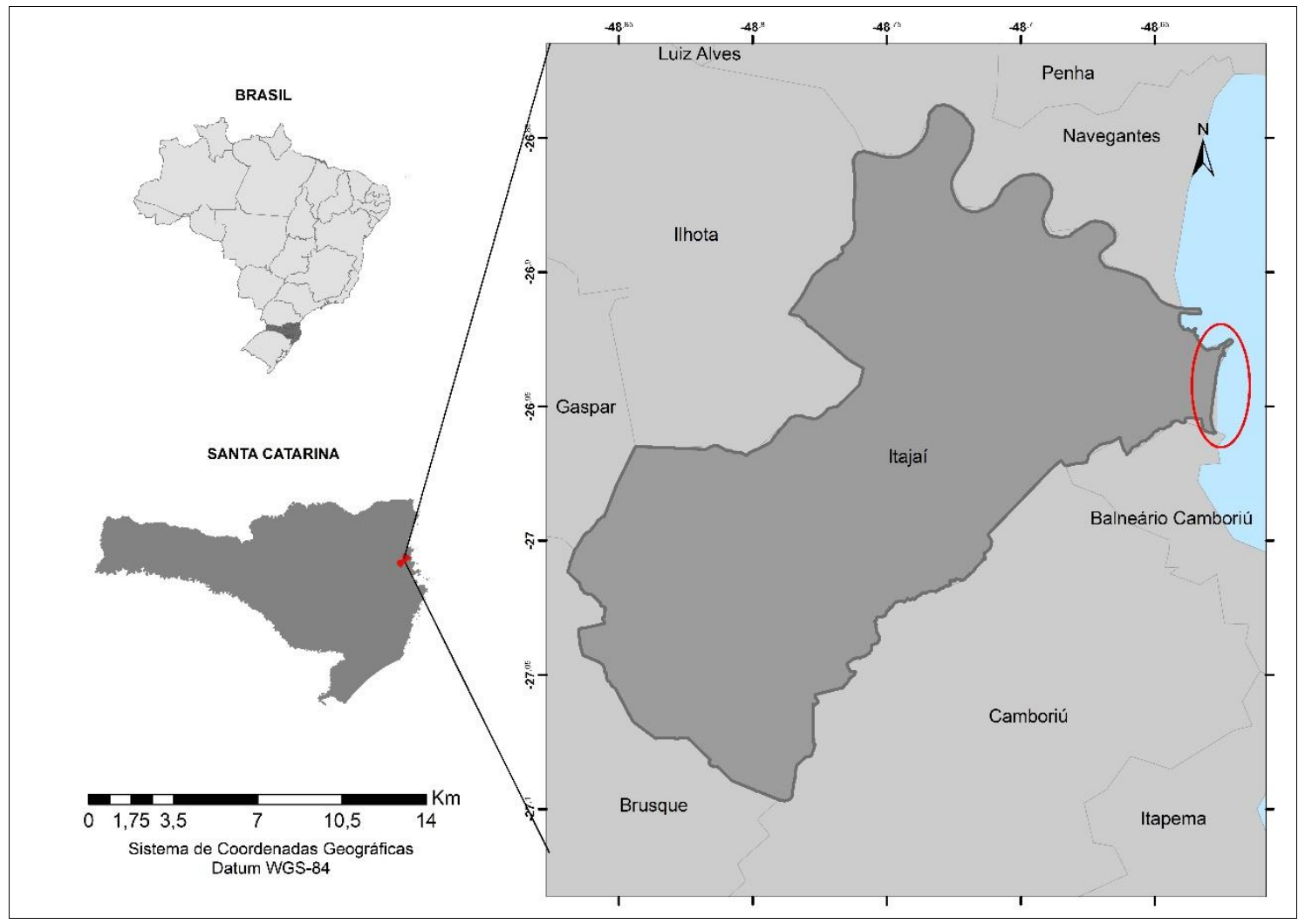

O município de Itajaí está totalmente inserido no bioma Mata Atlântica, sendo que a área de estudo se constitui de uma região de remanescentes florestais, isolados pela urbanização dos municípios de Balneário Camboriú e Itajaí, caracterizando-se como uma floresta urbana.

Com relação ao avifauna presente na área, Zimmermann (2012) destaca que no Parque Natural Municipal da Atalaia, incluso na área de estudo, a composição de riqueza ultrapassa 100 espécies. Branco e Fracasso (2012) destacam que no Saco da Fazenda, região já instituída como Unidade de Conservação (APA do Saco da Fazenda) e que se encontra adjacente à área 
analisada nesta pesquisa, vivem cerca de 50 espécies de aves, sendo 39 limícolas (água doce), 4 espécies de borda de cursos d'água ou visitantes pertencentes à Mata Atlântica, e 7 espécies de aves marinhas ou litorâneas. Já os dados disponíveis em UNIVALI (2016) apontam na área de estudo 115 espécies de aves.

Quanto a mastofauna foram identificadas na área de estudo 12 espécies que compõem o grupo da mastofauna terrestre, duas sendo classificadas apenas em nível de gênero, estando distribuídos em seis famílias, e uma espécie de mamífero aquático (UNIVALI, 2016).

\section{METODOLOGIA}

\section{CARACTERIZAÇÃO DO USO E COBERTURA DO SOLO}

O mapa de uso e cobertura do solo foi construído sobre o mosaico de imagens aéreas do Levantamento Aerofotogramétrico do Governo do Estado de Santa Catarina, datadas do ano de 2011, e que foi atualizado com o auxílio do software Google Earth.

As classes de uso e cobertura foram definidas com base no sistema da Agência Europeia de Meio Ambiente, o CORINE - Coordination of information on the Environment (Bossard; Feranec; Otahel, 2000), adaptadas para a realidade da área e divididas em dois grupos: (a) Tecido Urbano e (b) Espaços naturais ou seminaturais, totalizando 18 classes. A construção dos polígonos que representam as classes foi realizada em um Sistema de Informações Geográficas. De posse do mapa preliminar alguns dos locais mapeados foram sistematicamente visitados para a validação de algumas classes. Especificamente sobre a validação das classes de cobertura correspondentes às tipologias vegetais, o levantamento fitossociológico realizado neste trabalho também subsidiou este processo.

\section{CARACTERIZAÇÃO DAS TIPOLOGIAS VEGETAIS}

A caracterização das comunidades vegetais é informação base para a tomada de decisão frente à conservação dos ambientes naturais, pois elas são chave para a identificação e a definição dos limites de ecossistemas (Mueller-Dombois e Ellenberg, 1974; Matteucci e Colma, 1982). Durante este trabalho foram identificadas visualmente três tipologias vegetais: Floresta Ombrófila Densa (FLOD), Formação Pioneira com Influência Fluvio-marinha, o Mangue e a Formação Pioneira com Influência-marinha, a Vegetação de Restinga com fins de análise da paisagem. 
Na tipologia FLOD foi realizado um inventário florístico por meio do método dos quadrantes com base em Martins (1991). O levantamento desta tipologia vegetal foi necessário para identificar as espécies-modelo na análise do padrão funcional da paisagem (interação planta-animal).

\section{ANÁLISE DA INTERAÇÃO PLANTA-ANIMAL - ESPÉCIES-MODELO}

Esta análise considerou a dispersão realizada pela avifauna e mastofauna na manutenção da vegetação arbórea presente nas áreas recobertas pela Floresta Ombrófila Densa (FLOD). Neste trabalho, as espécies vegetais foram denominadas de espécies-modelo e as espécies da fauna de espécies-chave. Estas espécies-chave foram obtidas de UNIVALI (2016), enquanto as espécies-modelo foram levantadas em campo

Adaptando o conceito de espécie-modelo proposto por Kageyama et al. (2001), pode-se dizer que estas são "espécies escolhidas como amostras de grupos com características ecológico-genéticas comuns", ou seja, são aquelas que melhor representaram uma população amostrada em função de suas similaridades ecológicas e genéticas. Ainda que este estudo não utilize informações genéticas, partiu do princípio que as espécies arbóreas que são dispersas pela zoocoria têm características ecológicas similares, e que são comuns na vegetação secundária, poderiam ser consideradas espécies-modelo para o caso da área de estudo. As cinco espécies arbóreas que apresentaram o maior Índice de Valor de Importância (IVI), no levantamento fitossociológico empreendido nas áreas cobertas pela Floresta Ombrófila Densa (FLOD), foram escolhidas como espécies-modelo. Necessário destacar que o IVI proposto por Curtis e Machintoshi (1951) e mencionado em Salomão, Santana e Costa Neto (2012) e Freitas e Magalhães (2012) e corresponde a um valor numérico que é resultado do somatório dos valores de $\mathrm{ABr}$ (abundância relativa), FRr (frequência relativa) e DOr (dominância relativa).

\section{ANÁLISE DA ESTRUTURA ESPACIAL E PADRÃO FUNCIONAL DA PAISAGEM}

A metodologia desenvolvida neste estudo está em consonância com o que propõe Wiens (2002), que afirma que a análise da paisagem tem ênfase nas causas e consequências da heterogeneidade ou do padrão espacial de seus elementos. Também foram considerados nesta análise os conceitos acerca da estrutura e funcionamento da paisagem disponíveis em Barnes (2000), nos clássicos Forman (1995), Naveh e Lieberman, (1983) e Forman e Godron (1981). 
A estrutura espacial da paisagem foi determinada por meio da análise do mapa de uso e cobertura do solo produzido neste estudo. Inicialmente foi identificada a matriz tendo em conta que este não é apenas o elemento de maior cobertura, mas também aquele que apresenta a maior conectividade na paisagem. Uma vez determinada a matriz, os demais elementos foram caracterizados como manchas ou corredores.

O Padrão Funcional da Paisagem, considerando a interação planta-animal - dispersão, foi determinado pelo cruzamento das informações das espécies da flora (espécies-modelo) com as espécies da fauna (espécies-chave). Entretanto, na determinação das espécies-chave, é importante destacar que não foram considerados os parâmetros de abundância dos animais dispersores e tampouco o padrão de locomoção das espécies, como a capacidade de voo das aves, por exemplo. O padrão funcional referido neste estudo está traduzido na presença das espécies da fauna (espécies-chave) e indicadas na literatura como dispersoras das espéciesmodelo da flora e na conectividade da paisagem construída a partir da interação destas espécies.

\section{RESULTADOS E DISCUSSÃO}

\section{ESTRUTURA ESPACIAL DA PAISAGEM}

Sumariamente, o grupo dos Espaços naturais e seminaturais representa a maior cobertura na área com aproximadamente $83,7 \%$ dos 443,0 ha de toda a área terrestre, sendo que desses $70,72 \%$ de sua extensão é coberta por Floresta Ombrófila Densa e Formações Pioneiras (vegetação de Restinga e Manguezal). O grupo de classes que compõe o Tecido urbano, por sua vez, é responsável pela cobertura de $16,3 \%$ do total. Esta simples constatação ilustra a baixa alteração percentual relativa dos espaços naturais com relação ao tecido urbano na área de estudo.

Para entendimento da estrutura espacial na área de estudo, onde se pretende implantar a APA da Orla de Itajaí, foi necessário que as classes de uso e cobertura do solo fossem agrupadas em elementos estruturais da paisagem de acordo com o critério de características similares para a conectividade funcional da biodiversidade (Figura 2). 
Figura 2: Elementos da Estrutura Espacial da Paisagem, na região da orla de Itajaí, SC. Fonte: A autora (2016).

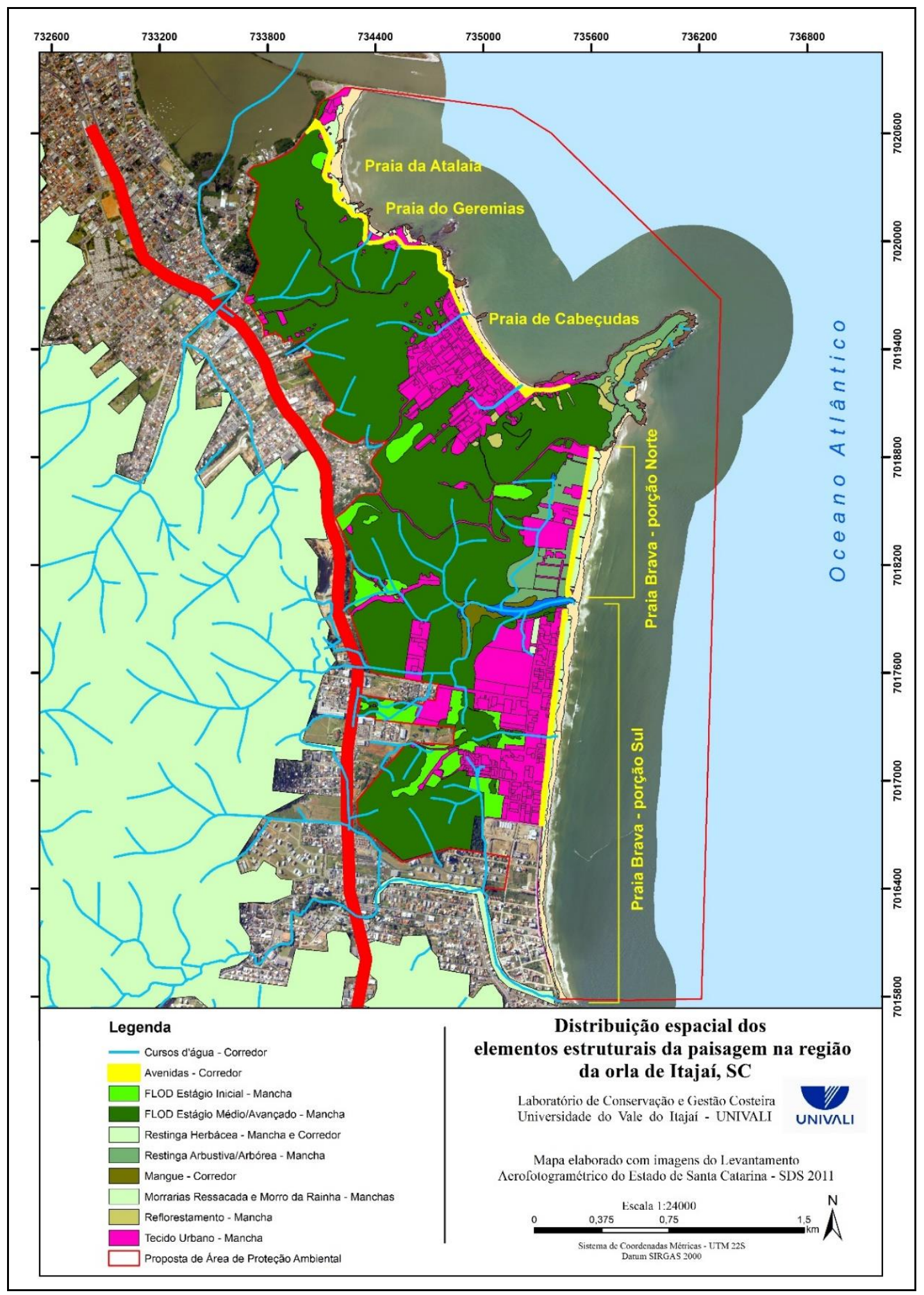

A classe de uso e cobertura que apresenta a maior conectividade e maior extensão em termos de área de cobertura corresponde a Floresta Ombrófila Densa em estágio 
médio/avançado de regeneração e, sendo assim foi considerada a matriz da paisagem dentro da região analisada nesta pesquisa. Uma vez definida a matriz, os arquivos digitais que compuseram o mapa de uso e cobertura do solo da área de estudo foram agrupados, considerando então a matriz, os tipos de mancha e os tipos de corredor. Na análise da estrutura espacial as morrarias do bairro da Ressacada e Morro da Rainha, apesar de estarem fora da área proposta como limite para a criação da APA no município de Itajaí, foram incluídas, pois representam uma provável fonte de sementes e propágulos, assim como potencialmente estabelece o fluxo genético de espécies da fauna que podem atuar como dispersores das espécies-modelo auxiliando na manutenção da FLOD.

A matriz composta pela FLOD, que também pode ser considerada como uma grande mancha de vegetação, determina a característica visual da paisagem com implicações sobre o microclima, a qualidade do ar e a presença evidente de membros da fauna, mesmo se tratando de uma mancha de floresta em meio a um ambiente urbano representado pelo município de Balneário Camboriú e porção central da cidade de Itajaí. Bedin (2013) também destaca a FLOD da Morraria da Ressacada e os seus serviços ambientais, assim como Ziembowicz (2011) e Oliveira (2016) na região dos promontórios costeiros, entre os quais está inserido o Canto do Morcego.

As manchas de FLOD inicial estão representadas ao longo de praticamente toda a área de estudo, sobretudo na porção central e sul. Nestas áreas existem árvores isoladas que podem estar atuando como trampolim ecológico, proporcionando que algumas espécies da avifauna possam transitar e cumprir seu papel ecológico de dispersores de sementes, auxiliando na manutenção da vegetação (Marenzi, 2004).

As manchas de FLOD na paisagem analisada constituem o que se pode chamar de uma floresta urbana, conceito que se refere à soma de todas as árvores, arbustos e gramados urbanos e solos permeáveis, localizados em ambientes onde os seres humanos são os principais condutores de seus tipos, quantidades e distribuição (Dobbs et al., 2011). Outros autores têm se referido ao termo floresta urbana como Salvati et al. (2017), Japelj et al. (2016) e Escobedo et al., (2011). Este conceito parece adaptar-se bem à realidade da área de estudo, considerando a importância da gestão territorial para conservá-la, uma vez que ela se encontra totalmente envolvida pelo tecido urbano de Itajaí.

A conservação de florestas em ambientes urbanos tem implicações na saúde humana, como foi demonstrado por Liu et al. (2013) em Guangzhou, China, onde demonstrou-se a 
capacidade significativa da vegetação urbana de reter alguns poluentes do ar, melhorando sua qualidade. Ainda com relação as implicações da vegetação na melhora da qualidade de vida, cita-se o estudo desenvolvido por Chen et al. (2014) na Austrália, país que em 2009 teve centenas de mortes causadas por fortes ondas de calor na cidade de Melbourne. Os autores utilizaram modelos matemáticos de previsão de temperatura para diferentes cenários vegetados e não vegetados e constataram redução de $0,5^{\circ}$ a $2^{\circ} \mathrm{C}$ quando a vegetação está presente. No Brasil, os autores Buckeridge (2015) e Santos et al., (2016), por exemplo, desenvolveram trabalhos que avaliam a importância das florestas urbanas e de áreas vegetadas nas cidades.

A mancha de Restinga arbustiva/arbórea ocupa grande parte da planície costeira da porção norte da Praia Brava e promontório do Canto do Morcego e está fragmentada por um corredor de Reflorestamento e também por uma estrada não pavimentada. Na planície esta mancha encontra-se fragmentada pela avenida Beira-mar que interrompe seu gradiente natural (herbácea - arbustiva - arbórea) e muito provavelmente dificulta o estabelecimento e a manutenção destas tipologias ao longo da área de estudo. Os prejuízos da fragmentação podem ser exercidos também pela rede viária (Fernandez, 2000). A Restinga herbácea foi considerada como mancha e corredor nesta análise. Como mancha ela representa um importante ecossistema fixador das dunas e garante a qualidade das areias, pois filtra o material em suspensão advindo sobretudo de veículos em trânsito na avenida Beira-mar. A presença desta mancha na paisagem, pode parecer em primeira instância mero detalhe, entretanto, a retirada desta vegetação pode ter implicações graves na qualidade das areias e, consequentemente, no turismo das praias da região.

O Reflorestamento também foi inserido em duas categorias (mancha e corredor). Contudo, como manchas constituídas predominantemente de espécies exóticas como Eucaliptus sp. e Pinus sp. existe uma tendência de que elas aumentem de tamanho e acabem por ocupar a posição de espécies nativas, fato que, pode tornar-se um problema em médio e longo prazo, descaracterizando a matriz (FLOD) na área. A presença de Pinus como espécie invasora é ressaltada em Dechoum e Ziller (2013).

Dentro da área de estudo, a mancha do Tecido Urbano está distribuída nas áreas de planície da região com pequenas porções nas morrarias. Contudo, esta mancha se distribui ao longo de toda a planície adjacente à região mapeada, incluindo a porção Sul da Praia Brava, aonde ela 
impede a conectividade entre o Morro da Rainha (Balneário Camboriú) e a matriz/mancha de FLOD.

A mancha de Tecido Urbano está em processo de expansão, fato que pode ser comprovado pelo avanço de moradias e desmatamentos, sobretudo em direção às morrarias que circundam o Parque Natural Municipal da Atalaia, alguns pontos das morrarias da Praia de Cabeçudas, além da planície da Praia Brava. Deste modo, aqui se ressalta a necessidade de medidas de gestão territorial capazes de acompanhar, inibir ou mesmo disciplinar este processo em detrimento da conservação dos ambientes naturais que ali estão estabelecidos.

No que concerne aos corredores, o do tipo remanescente é aquele que sucede a remoção ativa da maior parte da vegetação de uma área, é literalmente um remanescente vegetal linear e.g. pode ser a vegetação ripária poupada de supressão, limites de propriedades, vegetação no entorno das estradas e trilhas (Odum e Barret, 2007). Na área de estudo corresponde ao corredor de restinga herbácea, possibilitando o fluxo gênico desta formação vegetal, e desta forma, podendo contribuir com a estabilização das dunas.

Um corredor de perturbação é aquele que interrompe uma paisagem natural homogênea ao passo que também servem de habitat para algumas espécies, como uma linha de drenagem ou de transmissão de energia, estes corredores também podem atuar como filtros para determinadas espécies (Odum e Barret, 2007). Na área analisada, este tipo de corredor corresponde às avenidas Osvaldo Reis e Beira-mar, sendo que as vias de forma geral atuam como filtro e em algumas situações como sumidouro (Marenzi, 2004). Nesse caso, fragmentando abruptamente a FLOD na área de estudo e a FLOD na morraria da Ressacada.

Os corredores de perturbação, filtro e sumidouro na paisagem analisada, com alguma exceção para os cursos d'água, são aqueles responsáveis por fragmentá-la e com isso podem causar uma série de impactos no funcionamento ecossistêmico, entre eles a própria perda de habitat para algumas espécies animais e a alteração da dinâmica dos recursos naturais disponíveis (Sweatman, Layman e Fourqurean, 2017). A fragmentação da paisagem é um fator sabidamente responsável por inibir o movimento de animais terrestres e podem resultar em altas probabilidades de extinção de comunidades locais, isoladas nas manchas (van Langevelde, 2015). Tal constatação, contudo, já foi discutida e largamente observada e, tendo como base a teoria de Metapopulações, estabelece a relação entre fragmentação, perda de habitat ou de qualidade de habitat e extinção de populações e espécies (van Langevelde, 2015; Hanski, 1998). 
Ainda como corredor de perturbação tem-se os cursos d'água na região que podem atuar como filtro para algumas espécies, mas como fonte e habitat para outras (Forman, 1985), especialmente para espécies aquáticas da flora e da fauna.

Os corredores plantados são aqueles construídos por humanos com objetivos ecológicos e.g. para conectar manchas de vegetação, ou mesmo econômicos, e.g. para conter o avanço de pragas. Os corredores regenerados são aqueles que resultam "do restabelecimento de uma faixa de vegetação em uma matriz de paisagem” Odum e Barret (2007). Na região mapeada, estes corredores são representados pelo Reflorestamento no Canto do Morcego, que por sua forma linear, potencialmente constitui uma barreira para as espécies nativas. Desta forma, é possível dizer que atua também como filtro, função descrita por Forman (1985).

Por último, os corredores naturais ou de recurso são aqueles que em função de uma configuração natural da formação vegetal da área desenvolvem-se em padrões lineares (Odum e Barret, 2007). As florestas ripárias ao longo de cursos d'água e ainda as faixas de vegetação que se estabelecem ao longo de talvegues no terreno são bons exemplos deste tipo de corredor. A vegetação de Mangue e também a Mata Ciliar às margens da Lagoa do Cassino, atuam como corredores naturais ou de recurso e estão potencialmente promovendo o fluxo de espécies e integrando o padrão funcional paisagístico.

Além do propósito inicial essencialmente descritivo de quantificar a estrutura da paisagem (Lausch et al., 2015), tentativas foram feitas no sentido de identificar relações potenciais entre o padrão estrutural da paisagem e os processos espaço-temporais biológicos e não biológicos que ocorrem nela (Turner, 1989). Como por exemplo, a distribuição de espécies ou populações e biodiversidade, ou ainda, os efeitos da pedologia nos padrões florísticos observados (Mühlner et al., 2010; Walz e Syrbe, 2013), que aborda o padrão funcional da paisagem. Neste trabalho, a relação entre o padrão estrutural da paisagem e o processo biológico de dispersão de sementes por zoocoria é abordado no capítulo subsequente.

Wiens (2002) considera que o padrão funcional é a combinação dinâmica dos elementos estruturais (matriz, manchas e corredores), da composição (tipologias vegetais e uso do solo), e dos processos ecológicos em nível de paisagem. O processo ecológico, considerado aqui (dispersão das espécies-modelo pelas espécies-chave), tem sua base científica no cruzamento das informações disponíveis na bibliografia o que parece ser bastante plausível. Contudo, tal seleção não pretende esgotar as discussões e inferências que podem ser feitas acerca das inúmeras interações entre outras espécies na área de estudo. Nesta pesquisa, o objetivo foi 
somente incitar a demonstração da interdependência entre as espécies arbóreas e da fauna da região, no sentido de descrever parte do padrão que ocorre e com isso justificar a necessidade de conservar a área analisada.

\section{PADRÃO FUNCIONAL DA PAISAGEM}

Especificamente, para a análise do padrão funcional, que considerou a interação plantaanimal com base nas espécies-modelo e espécies-chave, foi necessário o levantamento vegetal. Neste levantamento foram identificados 526 indivíduos, de 93 espécies distribuídas em 39 famílias botânicas. Importante destacar que das 93 espécies identificadas, 86 são nativas da Mata Atlântica, ou seja, aproximadamente 92,5 \% delas pertencem a este bioma, indicando que apesar da área encontrar-se alterada pela ocupação humana que cresce em direção às morrarias, o ambiente ainda permanece com suas características naturais quando considerados os dados deste levantamento. Os valores das variáveis fitossociológicas podem ser observados no Quadro 1, contudo este trabalho ateve-se somente à observação do IVI, cuja interpretação dá uma ideia acerca do desempenho de uma espécie dentro da comunidade vegetal (Martins, 1991), sendo os cinco maiores valores de IVI o critério de seleção da espécie como espécie-modelo.

Quadro 2: Lista contendo os cinco maiores IVIs do levantamento fitossociológico. NOTA: Dr = Densidade relativa; $F r=$ Frequência relativa; $\mathbf{D o R}=$ Dominância relativa; $I V I$ = Índice de Valor de Importância.

\begin{tabular}{|c|cccccc|}
\hline Espécie & $\begin{array}{c}\mathbf{N}^{\mathbf{0}} \\
\text { Ind }\end{array}$ & Origem & Dr (\%) & Fr (\%) & DoR (\%) & IVI (\%) \\
\hline Pera glabrata (Schott) Poepp. ex Baill. & 45 & Nativa & 8,56 & 8,86 & 16,71 & $\mathbf{3 4 , 1 3}$ \\
Psidium cattleianum Sabine & 48 & Nativa & 9,13 & 7,95 & 6,67 & $\mathbf{2 3 , 7 5}$ \\
Calophyllum brasiliense Cambess. & 23 & Nativa & 4,37 & 4,32 & 7,06 & $\mathbf{1 5 , 7 5}$ \\
Alchornea triplinervia (Spreng.) M. Arg. & 18 & Nativa & 3,42 & 3,18 & 6,81 & $\mathbf{1 3 , 4 1}$ \\
Psychotria suterella Müll. Arg. & 27 & Nativa & 5,13 & 5,45 & 2,24 & $\mathbf{1 2 , 8 2}$ \\
\hline
\end{tabular}

Foram classificadas como as cinco espécies arbóreas predominantes na área de estudo segundo o IVI, em ordem de importância: 1) Seca-Ligeiro (Pera glabrata (Schott) Poepp. ex Baill.) com IVI de 34,13\%, 2) Araçá (Psidium cattleianum Sabine) com IVI de 23,75\%, 3) Olandi (Calophyllum brasiliense Cambess.) com IVI de 15,75\%, 4) Tanheiro (Alchornea triplinervia (Spreng.) M. Arg.) com IVI de 10,23\% e 5) Cafézinho-roxo-da-mata (Psychotria suterella Müll. Arg.), cujo IVI foi da ordem de 7,37\%. Todas estas espécies têm síndrome de 
dispersão pela zoocoria, atendendo aos critérios de espécie-modelo adaptado de Kageyama et al (2001).

Importante reforçar que a dispersão de sementes é uma das etapas mais críticas da reprodução vegetal, pois os propágulos precisam pousar em local favorável à germinação, longe ou não da planta-mãe, reduzindo a competição e o risco de predação (Howe, 1993). A importante interação das espécies-modelo com as espécies-chave elucidou o que aqui se entende como o Padrão Funcional da Paisagem.

Nesta pesquisa as espécies arbóreas indicadas pelo inventário florístico como espéciesmodelo e também denominadas por Marenzi (2004) como espécies-recurso ou espéciesmodelo, em função de produzirem frutos atrativos para a fauna, foram analisadas no sentido de identificar seus potenciais dispersores, e entre eles, selecionar as espécies-chave.

Considerando as informações disponíveis na bibliografia e disponíveis em UNIVALI (2016), foram escolhidas como espécies-chave para a dispersão das espécies-modelo quatro espécies representantes da avifauna, cujas informações biológicas e comportamentais têm como base FAMAI (2013), às quais: Dacnis cayana (Saíra-azul); Turdus rufiventris (Sabiálaranjeira); Turdus leucomelas (Sabiá-barranco); Tangara sayaca (Sanhaçu-cinzento). Também foram selecionadas como espécies-chave um representante do grupo da mastofauna: Cerdocyon thous (Cachorro-do-mato) e a Ordem Chiroptera.

A identificação das espécies-chave como dispersoras das espécies-modelo e estas como representantes da FLOD na área de estudo, possibilitou entender como os elementos paisagísticos interferem na funcionalidade da paisagem, conforme indicam Forman (1995) e Barnes (2000) voltados para as espécies-chave (Quadro 3).

Quadro 3: Elementos estruturais da paisagem e sua relação com as espécies-chave na orla de Itajaí, SC.

\begin{tabular}{|c|c|c|c|c|}
\hline \multicolumn{2}{|c|}{ MANCHAS } & \multicolumn{3}{|c|}{ CORREDORES } \\
\hline \multirow{2}{*}{ Elemento } & \multirow{2}{*}{ Tipo $^{1}$} & \multirow{2}{*}{ Elemento } & \multicolumn{2}{|c|}{ Funções ecológicas ${ }^{2}$} \\
\hline & & & Aves/Morcego & Cachorro-do-mato \\
\hline $\begin{array}{c}\text { FLOD } \\
\text { médio/avançado }\end{array}$ & $\begin{array}{c}\text { Remanescente/ } \\
\text { Recurso } \\
\text { Ambiental }\end{array}$ & Estradas & Filtro & Filtro \\
\hline FLOD inicial & Remanescente & Avenidas & Filtro & Filtro/Sumidouro \\
\hline $\begin{array}{c}\text { Restinga } \\
\text { arbustiva/arbórea }\end{array}$ & $\begin{array}{c}\text { Remanescente/ } \\
\text { Recurso } \\
\text { Ambiental } \\
\end{array}$ & Cursos d'água & Fonte & Fonte/Filtro \\
\hline Restinga herbácea & Remanescente & Restinga herbácea & Fonte & - \\
\hline
\end{tabular}




\begin{tabular}{|c|c|c|c|c|}
\hline Reflorestamento & Introduzida & Reflorestamento & - & - \\
\hline Tecido urbano & Distúrbio & Mangue/Mata ciliar & Condutor/Habitat/Fonte & Fonte \\
\hline
\end{tabular}

${ }^{1}$ Segundo Barnes (2000); ${ }^{2}$ Segundo Odum e Barret (2007).

O conjunto de manchas Remanescentes de FLOD médio/avançado é o elemento da paisagem que contém as espécies-modelo, trata-se de uma vegetação alterada e, portanto, foi classificada como uma mancha Remanescente, que ao prover de alimento e abrigo a todas as espécies-chave também é reconhecida como mancha Recurso Ambiental, destacando-se como elemento paisagístico de maior expressão funcional em razão de sua dimensão e segundo os dados da fauna avaliados nesta pesquisa, especialmente das espécies-chave.

Assim como as manchas de FLOD médio/avançado, as de Restinga arbustiva/arbórea foram consideradas do tipo Remanescente e Recurso Ambiental. Primeiro porque se tratam de tipologias visivelmente alteradas e, segundo, porque mesmo não havendo espécies-modelo na Restinga arbustiva/arbórea, as espécies-chave selecionadas provavelmente utilizam estes habitats como fonte de recursos, devido à sua capacidade de prover abrigo e alimentação eventual. Já as manchas de Restinga herbácea e FLOD inicial foram classificadas como do tipo Remanescente, muito embora a Restinga Herbácea possa prover de recursos algumas aves, especialmente as insetívoras, devido a presença de vegetação rasteira. A FLOD inicial é caracterizada pela predominância de vegetação herbácea, fator determinante para estas manchas não terem sido classificadas como de Recurso Ambiental.

Com relação à mancha de Reflorestamento, que é do tipo Introduzida, não foi identificada uma função ecológica para as espécies-chave. Contudo, foi possível observar em campo que algumas aves de rapina, muito provavelmente o Gavião-carrapateiro (Milvago chimachima) ou o Gavião-carijó (Rupornis magnirostris), espécies mencionadas em UNIVALI (2016) utilizam esta mancha para pousio. O mesmo se aplica para o corredor de Reflorestamento, que apesar de não exercer uma função ecológica evidenciada em Odum e Barret (2007), parece possibilitar pousio para aves e, quiçá, de descanso para a mastofauna local, mesmo com maior dificuldade para a espécie-chave, Cachorro-do-mato, considerando o que afirma Faria-Corrêa (2004) de que esta espécie, apesar de habitar locais relativamente alterados, não é encontrada em locais destituídos de Mata Nativa. 
O Tecido Urbano foi considerado uma mancha Distúrbio para as espécies-chave selecionadas nesta pesquisa, contudo durante todos os trabalhos de campo empreendidos observou-se que no bairro Cabeçudas existe um grande número de aves utilizando terrenos baldios, jardins e outras áreas urbanas vegetadas como local de alimentação e/ou pousio. Esta constatação visual, potencialmente revela a importância do padrão urbanístico pouco adensado daquele bairro para a manutenção das espécies-chave do grupo avifauna na área de estudo. Vale destacar, ainda, que a urbanização ao descaracterizar os ambientes naturais, tem grande implicância na redução da riqueza desse grupo faunístico (Silva et al, 2014).

Também vale destacar que o Cachorro-do-mato foi fotografado em uma mancha de FLOD médio/avançado imediatamente adjacente ao bairro de Cabeçudas, corroborando o fato de frequentarem as bordas de matas e locais perturbados pela ação do homem beneficiando-se, em alguns casos, dos rejeitos produzidos por humanos em sua dieta onívora (Faria-Corrêa; 2004; Rocha et al. 2008). Esta espécie "devido a um alto consumo de frutos" é considerada uma boa dispersora de sementes (Cheida et al., 2011 p. 245).

Os corredores, por sua vez, no que diz respeito às Estradas e Avenidas, representam a função de filtro tanto para a espécie-chave da mastofauna quanto para as espécies da avifauna. Ainda que a única informação referenciada demonstre que o atropelamento vitime somente a espécie Cachorro-do-mato (Cheida et al., 2011; Faria-Corrêa; 2004; Rocha et al. 2008), é possível considerar que as aves e morcegos, quando em voos baixos, sofrem danos pelo tráfego de veículos. Ainda, considerando o comportamento do Cachorro-do-mato (Cheida et al., 2011; Faria-Corrêa, 2004; Rocha et al. 2008), as avenidas presentes na área de estudo atuam como Sumidouros, em horários de tráfego intenso.

Os corredores de paisagem constituídos pelos cursos d'água foram classificados como Fonte, considerando o seu potencial de fornecimento de recurso alimentar (frutos e sementes), para as espécies-chave da avifauna, sumariamente frugívoras (Nishida, Naide e Pagnin, 2014; Silva et al., 2014; Gressler, Pizo e Morellato, 2006), e mastofauna (Sette, 2012; Silva Júnior e Pereira, 2009; Mello, 2005; Novaes, 2010; Gagetti, Piratelli e Piña-Rodrigues, 2016; Gressler, Pizo e Morellato,2006). Contudo, alguns elementos dos cursos d'água também podem oferecer pousio e banho (estas funções não são classificadas por Forman, 1995) para as espécies-chave, bem como para outras espécies presentes na área, como é o caso da Garçabranca-pequena (Egretta thula) e da Batuíra-de-bando (Charadrius semipalmatus), esta última uma espécie migratória (UNIVALI, 2016). 
A Restinga Herbácea é também indicada como corredor e fonte. Os cursos d'água também foram classificados como Filtro para a mastofauna, pois podem impedir naturalmente a travessia do Cachorro-do-mato e de outros mamíferos na paisagem devido à dificuldade de nado em casos de maior profundidade, como o caso da Lagoa do Cassino.

Quanto ao mangue e as matas ciliares presentes na área de estudo, foram identificados como corredores do tipo Condutor/Habitat/Fonte para aves e morcegos e como Fonte para o Cachorro-do-mato. As matas ciliares têm potencial de ser habitadas pelas espécies-chave, especialmente a Turdus leucomelas, mas pela situação de pouca largura destas matas, pode não ser a realidade da Dacnis cayana, que vive preferencialmente no interior das matas (FAMAI 2013). Potencialmente, outras espécies da avifauna utilizam estes ambientes para alimentar-se e/ou abrigar-se como é o caso daquelas demonstradas na (Figura 2); outras utilizam as matas ciliares da área de estudo justamente por apresentarem guilda alimentar piscívora como o Martim-pescador-grande (Megaceryle torquata) e o Martim-pescadorpequeno (Chloroceryle americana) UNIVALI (2016) destacando a importância destes ambientes na funcionalidade da paisagem.

Ainda que não tenha sido considerada a capacidade de voo ou deslocamento das espécieschave, assim como em Marenzi (2004), a conectividade funcional entre a região analisada e a morraria da Ressacada, já mencionada como importante fonte de fluxo genético de espécies, está potencialmente mais associada ao grupo da avifauna encontrado na área. Isto se deve ao fato de que a avenida Osvaldo Reis representa perigo de atropelamento (corredor sumidouro) para a mastofauna terrestre; como é o caso do Cachorro-do-mato; para este animal FariaCorrêa (2004) afirma ser a morte por atropelamento uma das principais causas, destacando os malefícios da intervenção antrópica na paisagem e reforçando a necessidade restabelecer a conectividade entre os dois fragmentos de Mata Atlântica (área de estudo e morrarias da Ressacada).

A relação sinérgica planta-animal identificada na área de estudo, foi realizada de forma indireta, sem a determinação de parâmetros como a abundância e sem mais aprofundamento na questão comportamental da fauna, além de seus hábitos alimentares (frugivoria). Contudo, ainda que de maneira indireta e elementar, aferir esta interação dá uma ideia da necessidade de proteger o fragmento de vegetação analisado nesta pesquisa, pois em paisagens fragmentadas pela ação humana o monitoramento da interação planta-animal pode significar a sobrevivência ou mesmo a ampliação das comunidades naturais (Pivello et al. 2006). 


\section{CONSIDERAÇÕES FINAIS}

O principal agente de fragmentação na área de estudo são as vias de tráfego, com destaque para as avenidas Osvaldo Reis e Beira-mar. Portanto, é importante restabelecer a conectividade em termos espaciais entre a morraria da Ressacada e a área de estudo e também dentro dessa, estabelecendo estruturas de passa-fauna e normas de redução de velocidade de veículos. De maneira geral, a fragmentação da paisagem e a ausência de conectividade espacial, tem efeito nocivo sobretudo na fauna terrestre, especialmente o Cachorro-do-mato, considerada espécie-chave neste estudo. A construção ou melhora da conectividade para este grupo é um ponto a ser pensado em termos de gestão da futura Unidade de Conservação que deverá ser implementada na região da orla de Itajaí.

A determinação da População Viável Mínima (PVM) das espécies-chave seria um importante mecanismo de aferição da longevidade do sistema ecológico presente, munindo de informações os gestores, visitantes e comunidade envolvida pela criação da APA no município de Itajaí. Igualmente importante seria aprofundar o conhecimento das aves escolhidas como espécies-chave, no sentido de entender qual é seu real papel na conectividade das morrarias da região e se de fato elas reduzem o grau de isolamento da área analisada.

É deveras indiscutível a importância que a mancha/matriz de mata atlântica que recobre a área de estudo tem, não somente para biodiversidade, mas também para a manutenção da qualidade de vida das populações humanas de entorno e visitantes. Dotada de notável beleza cênica, a área de estudo certamente proporciona às pessoas bem-estar e momentos de relaxamento, aspectos que também podem ser exploradas por meio de trabalhos de percepção ambiental. Importante considerar, ainda, que as florestas urbanas têm influência direta na qualidade do ar e também na manutenção do conforto térmico em termos de microclima e que tal constatação deve ser entendida pelo poder público no sentido de expandir as áreas verdes nos centros urbanos.

Por fim, a respeito dos subsídios para a efetivação da APA em Itajaí, tem-se que o Plano de Manejo, que é o instrumento legal que normatiza o seu funcionamento, devendo contemplar, sobretudo, a contenção do processo de fragmentação dos habitats em função do aumento da malha urbana dentro da área e também no seu entorno, com especial atenção à contenção da ocupação nas morrarias. O poder público municipal deve compreender que em nível de 
paisagem existe uma relação de fluxo gênico entre a morraria da Ressacada e a área de estudo e que, portanto, a proteção e gestão destas áreas deve ser integrada.

\section{REFERÊNCIAS BIBLIOGRÁFICAS}

BARNES, Thomas G. Landscape Ecology and Ecosystems Management. Cooperative Extension Service, Lexington, n. 76, p.1-8, 2000.

BEDIN, F. A. Ecologia da Paisagem como subsídio para implantação do Parque Municipal da Ressacada - Itajaí, SC. 2013. 140 f. Dissertação (Mestrado) - Curso de Pósgraduação em Ciência e Tecnologia Ambiental, Universidade do Vale do Itajaí, Itajaí, 2013.

BOSSARD, M.; FERANEC, J.; OTAHEL, J. CORINE land cover technical guide: Addendum 2000. Copenhagen: Copenhagen, 2000. 105 p.

BRANCO, J.O; FRACASSO, H. A. A. Avifauna Aquática. In: POLETTE, M.; MARENZI, R.C.M. e SANTOS, C. F. (Org.) Atlas Socioambiental de Itajaí. Editora da Univali, 2012. BRASIL. Lei $\mathrm{n}^{\circ}$ 9985, de 18 de janeiro de 2000. Sistema Nacional de Unidades de Conservação. Brasília, 22 jan. 2000.

BUCKERIDGE, M. Árvores urbanas em São Paulo: planejamento, economia e água. Estudos Avançados, [s.1.], v. 29, n. 84, p.85-101, ago. 2015. FapUNIFESP (SciELO). http://dx.doi.org/10.1590/s0103-40142015000200006.

BUREL, F.; BAUDRY, J. Landscape Ecology: Concepts, Methods and Applications. [s.i]: Science Publisher Inc, 2004.

CHEIDA, C. C.; NAKANO-OLIVEIRA, E.; FUSKO-COSTA, R.; ROCHA-MENDES, F.; QUADROS, J. Ordem Carnívora. In: REIS, N. R.; PERACCHI, A. L.; PEDRO, W. A.; LIMA, I. (Ed.). Mamíferos do Brasil. 2. ed. Londrina: Nelio R. dos Reis, 2011. p. 235-288.

CHEN, D. et al. Urban vegetation for reducing heat related mortality. Environmental Pollution, [s.1.], v. 192, p.275-284, set. 2014. Elsevier BV. http://dx.doi.org/10.1016/j.envpol.2014.05.002.

CONNELL, J. H. Diversity in Tropical Rain Forests and Coral Reefs. Science, [s.i], v. 199, n. 4335, p.1302-1310, mar. 1978.

CULLEN J.L.; RUDRAN, R.; VALLADARES-PADUA, C. (Org.). Métodos de estudos em Biologia da Conservação e Manejo da Vida Silvestre. 2. ed. Curitiba: UFPR, 2012.

CURTIS, J. T.; MCINTOSH. An upland forest continuum in the prairie-forest border region of Wisconsin. Ecology, Washington, v. 32, p. 476 - 496, 1951.

DECHOUM, M. de S.; ZILLER, S. R. Métodos para controle de plantas exóticas invasoras. Biotemas, [s.1.], v. 26, n. 1, p.69-77, 18 fev. 2013. Universidade Federal de Santa Catarina (UFSC). http://dx.doi.org/10.5007/2175-7925.2013v26n1p69.

DOBBS, C., ESCOBEDO, F., ZIPPERER, W., 2011. A framework for developing urban forest ecosystem services and goods indicators. Landscape and Urban Planning 99, 196206.

ESCOBEDO, F. J. et al. Urban forests and pollution mitigation: Analyzing ecosystem services and disservices. Environmental Pollution, [s.1.], v. 159, n. 8-9, p.2078-2087, ago. 2011. Elsevier BV. http://dx.doi.org/10.1016/j.envpol.2011.01.010.

FAMAI - Fundação de Meio Ambiente de Itajaí. Guia das Aves do Parque Natural Municipal da Atalaia. 2013. Disponível em: file://C:/Users/2422425/Downloads/Guia\%20miolo.pdf. Acesso em: 26 set. 2016. 
FARIA-CORRêA, M. Ecologia de Graxains (Carnivora: Canidae; Cerdocyon thous e Pseudalopex Gymnocercus) em um remanescente de Mata Atlântica na Região Metropolitana de Porto Alegre - Parque Estadual de Itapuã - Rio Grande Sul, Brasil. 2004. 108 f. Dissertação (Mestrado) - Curso de Pós-graduação em Ecologia, Universidade, Porto Alegre, 2004.

FERNANDEZ, F. O poema imperfeito: Crônicas de Biologia, Conservação da Natureza e seus Heróis. Curitiba: UFPR, 2000. 260 p.

FORMAN, R. T. T. e GODRON, M. Patches and structural components for a landscape ecology. Bioscience, EUA, v. 31, n. 10, 1981. p. 733-740.

FORMAN, R. T. T. Land mosaics: The ecology of landscapes and region. New York: Cambridge Press, 1995. 632 p.

FREITAS, W. K. de; MAGALHÃES, L. M. S. Métodos e Parâmetros para Estudo da Vegetação com Ênfase no Estrato Arbóreo. Floresta e Ambiente, [s.1.], v. 19, n. 4, p.520540, 2012. FapUNIFESP (SciELO). http://dx.doi.org/10.4322/floram.2012.054.

GAGETTI, B. L.; PIRATELLI, A. J.; PIÑA-RODRIGUES, F. C. M.. Fruit color preference by birds and applications to ecological restoration. Brazilian Journal of Biology, [s.1.], v. 76, n. 4, p.955-966, dez. 2016. FapUNIFESP (SciELO). http://dx.doi.org/10.1590/1519$\underline{6984.05115 .}$.

GRESSLER, E.; PIZO, M. A.; MORELLATO, L. P.C. Polinização e dispersão de sementes em Myrtaceae do Brasil. Revista Brasileira de Botânica, [s.1.], v. 29, n. 4, p.509-530, dez. 2006. FapUNIFESP (SciELO). http://dx.doi.org/10.1590/s0100-84042006000400002.

HANSKI, I. Metapopulation dynamics. Nature, [s.1.], v. 396, n. 6706, p.41-49, 5 nov. 1998. Springer Nature. http://dx.doi.org/10.1038/23876.

HOWE, H. F. Aspects of variation in a neotropical seed dispersal system. Vegetatio, Perth, v. 107/108, n. 1, p. 149-162, 1993.

INPE - INSTITUTO NACIONAL DE PESQUISAS ESPACIAIS. Projeto PRODES: monitoramento da floresta amazônica brasileira por satélite. 2015. Disponível em: http://www.obt.inpe.br/prodes/prodes_1988_2014.htm. Acesso em: 07 jul. 2015.

IUCN - International Union for Conservation of Nature. Priority Area 1: Protected areas conserving nature. Disponível em: http://www.iucn.org/about/work/programmes/gpap_home/gpap_biodiversity/>. Acesso em: 02 dez. 2015.

JAPELJ, A. et al. Latent preferences of residents regarding an urban forest recreation setting in Ljubljana, Slovenia. Forest Policy and Economics, [s.1.], v. 71, p.71-79, out. 2016. Elsevier BV. http://dx.doi.org/10.1016/j.forpol.2015.10.003.

KAGEYAMA, P.; GANDARA, F.; CAVALCANTI, T. 2001. Estudo da biodiversidade em parcelas permanentes grandes, tendo com base espécies arbóreas raras, visando a conservação genética. In: GARAY, I; DIAS, B. Conservação da Biodiversidade em Ecossistemas Tropicais. Petrópolis: Editora Vozes, 2001, p. 370-375.

KOLLMANN, J. Dispersal of fleshy-fruited species: a matter of spatial scale? Urban \& Fischer Verlag, Zürich, v. 3/. p.29-51, 2000.

LAUSCH, A. et al. Understanding and quantifying landscape structure - A review on relevant process characteristics, data models and landscape metrics. Ecological Modelling, [s.1.], v. 295, p.31-41, Jan. 2015. Elsevier BV. http://dx.doi.org/10.1016/j.ecolmodel.2014.08.018. 
LIU, L. et al. The dust retention capacities of urban vegetation - a case study of Guangzhou, South China. Environmental Science and Pollution Research, [s.1.], v. 20, n. 9, p.66016610, 23 abr. 2013. Springer Nature. http://dx.doi.org/10.1007/s11356-013-1648-3.

MARENZI, R.C. Ecologia da Paisagem da morraria da Praia Vermelha (SC): subsídio à Conservação da Biodiversidade de uma área costeira. 2004. $216 \mathrm{f}$. Tese (Doutorado) Curso de Ciências Florestais, Universidade Federal do Paraná, Curitiba, 2004.

MARTINI, A. M. Z.; SANTOS, F. A. M. dos. Effects of distinct types of disturbance on seed rain in the Atlantic forest of NE Brazil. Plant Ecology, [s.l.], v. 190, n. 1, p.81-95, 20 dez. 2006. Springer Nature. http://dx.doi.org/10.1007/s11258-006-9192-6

MARTINS F. R., SANTOS F. A. M. Técnicas usuais de estimativa da biodiversidade. In: Anais do I Congresso Brasileiro de Conservação e Manejo da Biodiversidade; 1999; Ribeirão Preto. Revista Holos. Ribeirão Preto: Universidade Estadual Paulista, 1999, 1: 236-267.

MATTEUCCI, S.D.; COLMA, A. Metodologia para el estudio de la vegetación. Washington: The General Secretarial of The Organization of American States; 1982. (Série Biologia - Monografia, n. 22).

MELLO, M. A. R. et al. Size-based fruit selection of Calophyllum brasiliense (Clusiaceae) by bats of the genus Artibeus (Phyllostomidae) in a Restinga area, southeastern Brazil. Acta Chiropterologica, [s.1.], v. 7, n. 1, p.179-182, jun. 2005. Museum and Institute of Zoology at the Polish Academy of Sciences. http://dx.doi.org/10.3161/17335329(2005)7[179:sfsocb]2.0.co;2.

MUELLER-DOMBOIS, D; ELLENBERG, H. Aims and methods of vegetation ecology. New York: John Wiley \& Sons; 1974.

MÜHLNER, S., KORMANN, U., SCHMIDT-ENTLING, M.H., HERZOG, F., BAILEY, D. Structural versus functional habitat connectivity measures to explain bird diversity in fragmented orchards. J. Landsc. Ecol. v.3. c.1. p.52-63. 2010

NAVEH, Z.; LIEBERMAN, A. S. Landscape Ecology: Theory and Application. Nova Iorque: Spring Verlag, 1983.

NISHIDA, S. M.; NAIDE, S. S.; PAGNIN, D. Plantas que atraem aves e outros bichos. São Paulo: Cultura Acadêmica, 2014. 99 p.

NOVAES, R. L. M. N.; MENEZES JÚNIOR, L. F.; DUARTE, A. C.; FAÇANHA, C. S. Consumo de Psychotria suterella Muell. Arg. (Rubiaceae) por morcegos no sudeste do Brasil. Chiroptera Neotropical, Brasília, v. 16, n.1, p. 535 -538, jul. 2010.

ODUM, E. P.; BARRET, Gary W. Fundamentos de Ecologia. 5. ed. São Paulo: Thomson, 2007.

OLIVEIRA, C. R. de. Serviços Ecossistêmicos prestados pelos Promontórios Costeiros no litora Centro-norte de Santa Catarina. 86 f. Dissertação (Mestrado) - Curso de Pósgraduação em Ciência e Tecnologia Ambiental, Universidade do Vale do Itajaí, Itajaí, 2016.

PIMM, S. L. et al. The biodiversity of species and their rates of extinction, distribution, and protection. Science, [s.1.], v. 344, n. 6187, 2014.

PIVELLO, V. R. et al. Chuva de sementes em fragmentos de Floresta Atlântica (São Paulo, SP, Brasil), sob diferentes situações de conectividade, estrutura florestal e proximidade da borda. Acta Botanica Brasilica, [s.1.], v. 20, n. 4, p.845-859, dez. 2006. FapUNIFESP (SciELO). http://dx.doi.org/10.1590/s0102-33062006000400010.

ROCHA, V. J. et al. Feeding habits of the crab-eating fox, Cerdocyon thous (Carnivora: Canidae), in a mosaic area with native and exotic vegetation in Southern Brazil. Revista Brasileira de Zoologia, [s.1.], v. 25, n. 4, p.594-600, dez. 2008. FapUNIFESP (SciELO). http://dx.doi.org/10.1590/s0101-81752008000400003. 
SALOMÃO, R.P; SANTANA, A.C.; COSTA NETO, S.V. Construção de Índices de Valor de Importância de espécies para Análise Fitossociológica de Floresta Ombrófila através de análise multivariada. Floresta, Curitiba, v. 42, p.115-128, Jan/Mar. 2012.

SALVATI, L. et al. Forest and the city: A multivariate analysis of peri-urban forest land cover patterns in 283 European metropolitan areas. Ecological Indicators, [s.1.], v. 73, p.369-377, fev. 2017. Elsevier BV. http://dx.doi.org/10.1016/j.ecolind.2016.09.025

SANTOS, O. dos A. et al. Composition and richness of woody species in riparian forests in urban areas of Manaus, Amazonas, Brazil. Landscape And Urban Planning, [s.1.], v. 150, p.70-78, jun. 2016. Elsevier BV. http://dx.doi.org/10.1016/j.landurbplan.2016.03.004.

SETTE, I. M.S. Interação morcego-fruto: Estado da arte no Brasil e um estudo da chuva de sementes por aves e morcegos em uma área do cerrado em Brasília. 2012. $84 \mathrm{f}$. Dissertação (Mestrado) - Curso de Pós-graduação em Ecologia, Universidade de Brasília, Brasília, 2012.

SILVA JÚNIOR, M. C. da; PEREIRA, B. A. da S. 100 Árvores do Cerrado - Matas de Galeria: guia de campo. Brasília: Ed. Rede de Sementes do Cerrado, 2009. 288 p.

SILVA, F. C. et al. Composição da comunidade de aves em área urbana no sul do Brasil. Neotropical Biology and Conservation, [s.1.], v. 9, n. 2, p.78-90, 3 jun. 2014. UNISINOS - Universidade do Vale do Rio Dos Sinos. http://dx.doi.org/10.4013/nbc.2014.92.02.

SOSMA - SOS MATA ATLÂNTICA. Atlas dos Remanescentes Florestais da Mata Atlântica Período 2014 - 2015. São Paulo, 2016.

SWEATMAN, J. L.; LAYMAN, C. A.; FOURQUREAN, J. W. Habitat fragmentation has some impacts on aspects of ecosystem functioning in a sub-tropical seagrass bed. Marine Environmental Research, [s.1.]. No prelo. Fev. 2017. Elsevier BV. http://dx.doi.org/10.1016/j.marenvres.2017.02.003.

TROLL, G. Landscape Ecology (geo-ecology) and bio-ceonology: a terminology study. Geoforum n.8, p.43-46. 1971.

UNIVALI - Universidade do Vale do Itajaí. Estudos de Delimitação/Demarcação APA/ Parque na Orla de Itajaí - Relatório Técnico I. Itajaí, 2016.

VAN LANGEVELDE, F. Modelling the negative effects of landscape fragmentation on habitat selection. Ecological Informatics, [s.1.], v. 30, p.271-276, nov. 2015. Elsevier BV. http://dx.doi.org/10.1016/j.ecoinf.2015.08.008.WALZ, U., SYRBE, R.-U., 2013. Linking landscape structure and biodiversity. Ecol. Indic. 31, 1-5.WIENS, J. A. Central Concepts and Issues of Landscape Ecology. In: GUTZWILLER, Kevin J. Applying Landscape Ecology in Biological Conservation. Nova Iorque: Springer Science+Bussiness Media, 2002. p. 321.WUNDERLE, J. M. The role of animal seed dispersal in accelerating native forest regeneration on degraded tropical lands. Forestry Ecology and Management, Palmer, v. 99, p.223-235, 1997.ZIEMBOWICZ, T. Ecologia da Paisagem dos Maciços Costeiros do Centro-norte de Santa Catarina. 111 f. Dissertação (Mestrado) - Curso de Pós-graduação em Ciência e Tecnologia Ambiental, Universidade do Vale do Itajaí, Itajaí, 2011.ZIMMERMANN, C. Aves. IN: POLETTE, M.; MARENZI, R.C.M. e SANTOS, C. F. (Org.) in: Atlas Socioambiental de Itajaí. Editora da UNIVALI, 2012.

Recebido em 20 de julho de 2017. Aceito em 05 de dezembro de 2017. 